\title{
CARACTERIZAÇÃO DE RESÍDUOS DA SUINOCULTURA, DA INDÚSTRIA TÊXTIL E DE URINA HUMANA PARA APLICAÇÃO COMO FERTILIZANTE
}

\author{
Leandro Mazzuco de Aguida1, Haline Depiné², Daniela Aparecida Oliveira³, \\ Vander Kaufmann ${ }^{4}$ e Adilson Pinheiro 5
}

\begin{abstract}
Resumo: O uso dos resíduos orgânicos na agricultura é uma opção viável do ponto de vista agrícola e econômico em razão da ciclagem de nutrientes. No entanto, questionamentos são efetuados em relação aos impactos ambientais que podem ser gerados. O presente trabalho teve como objetivo quantificar as espécies químicas dos resíduos da suinocultura, da indústria têxtil e da urina humana, na perspectiva de seu reuso como fertilizante na atividade agrícola. Para a determinação das concentrações das espécies químicas, utilizou-se o cromatógrafo de troca iônica aniônica e catiônica e o analisador de carbono orgânico total para as concentrações de carbono das amostras. Os resultados indicaram que os dejetos líquidos suínos (DLS) e a urina humana podem suprir a necessidade de potássio em solos cujo teor de potássio é considerado de valor médio, enquanto o lodo têxtil apresentou valor 9 vezes menor. Para solos com teor muito baixo a aplicação de DLS e urina humana podem ser de $100 \mathrm{~m}^{3} \mathrm{ha}^{-1}$ ano-1, enquanto em solos com teor médio de potássio, o DLS e urina humana tem que ser reduzidos pela metade. No caso do fósforo, a urina humana supre a necessidade quando o teor deste elemento no solo for médio, enquanto no DLS, o valor observado é 20 vezes menor e no lodo têxtil 37 vezes menor. Para atender a necessidade de solos com teor muito baixo, a urina humana pode ser aplicada a $100 \mathrm{~m}^{3}$. ha $\mathrm{a}^{-1}$ ano-1, porém o DLS e lodo têxtil não atenderiam esta necessidade.
\end{abstract}

Palavras-chave: Suinocultura. Caracterização de resíduos. Fertilização de solo.

\section{Introdução}

Técnicas que agregam o uso de resíduos como fonte de fertilização para substituição parcial ou total de adubos químicos vêm sendo estudadas e testadas visando utilizá-los como fonte renovável, além de obter redução nos custos de produção (MENEZES; SALCEDO 2007; SEIDEL et al., 2010; ARRUDA et al., 2010; MONDARDO et al., 2011; CASSOL et al., 2012). O uso de resíduos em áreas agrícolas está diretamente relacionado à minimização dos efeitos do desenvolvimento da sociedade contemporânea, efeitos estes, nem sempre benéficos para o meio ambiente, à vida e ao próprio ser humano (SCHERER; BALDISSERA; NESI, 2007; CASTRO; PEREIRA; PAIVA, 2009; KVARNSTRÖM et al., 2006).
Algumas dúvidas sobre dosagem e efeitos sobre o meio ambiente devem ser sanadas. Os fertilizantes orgânicos usados na agricultura podem ser considerados uma alternativa racional quando empregados juntamente com as práticas agrícolas adequadas (NOGUEIRA et al., 2007; CORRÊA; BENITES; REBELLATTO, 2011). $O$ uso adequado dos resíduos depende de diferentes fatores, envolvidos nas características químicas e físicas dos mesmos (HIGASHIKAWA; SILVA; BETTIOL, 2010) podendo ou não ser utilizados como nutrientes para as plantas.

O crescente aumento dos custos de produção nas lavouras comerciais faz com que os recursos disponíveis precisem ser maximizados de modo a viabilizar a atividade. $\mathrm{O}$ uso dos resíduos orgânicos na agricultura pode ser uma opção viável do ponto de vista agrícola e econômico em

\footnotetext{
${ }^{1}$ E-mail: leandrom@tpa.com.br

²E-mail: hali_ne@hotmail.com

${ }^{3}$ E-mail: danioliveira7@yahoo.com.br

${ }^{4}$ E-mail: vanderkaufmann@gmail.com

${ }^{5}$ E-mail: pinheiro@furb.br

FURB - Universidade Regional de Blumenau, Programa de Pós-Graduação em Engenharia Ambiental. CAMPUS II Complexo Tecnológico. Rua São Paulo, 3250 - Itoupava Seca. CEP 89.030-000 - BLUMENAU - SC, Brasil
} 


\section{REA - Revista de estudos ambientais (Online) v.18, n. 2, p.52-61, jul./dez. 2016}

razão da ciclagem de nutrientes. Esses fatos geram um aumento na demanda por informações com a finalidade de avaliar a viabilidade ambiental para o reuso de alguns resíduos (MENEZES; SALCEDO, 2007; SANTOS; MEURER, 2012; BASSO et al., 2012;). Por outro lado, estudos têm demonstrado que as aplicações de resíduo de lodo têxtil e dejeto líquido suíno (DLS) podem comprometer a qualidade dos recursos hídricos (GUARDINI et al., 2012; GIROTTO et al., 2013).

Dificilmente as necessidades nutricionais de uma determinada cultura serão supridas de forma equilibrada somente com a utilização de materiais orgânicos, pois a concentração de nutrientes neles existente difere, na maioria das vezes, das relações comumente requeridas. A falta ou excesso deles dificulta e onera o desenvolvimento das culturas. O cloreto, por exemplo, age no metabolismo da agua, transpiração e fotossíntese das plantas. $O$ excesso de cloro no solo pode resultar em complicações para algumas culturas. A toxidez do cloro é caracterizada pela queima das margens das folhas localizadas externamente na planta (EMBRAPA, 2004; CARVALHO; SOUZA, SOUZA, 2005).

O potássio é regulador do potencial osmótico das células vegetais, além de ativar muitas enzimas envolvidas na respiração e na fotossíntese. $O$ potássio aplicado com o adubo orgânico comporta-se como mineral desde a aplicação, uma vez que ele não faz parte de nenhum composto orgânico estável, portanto, não precisa sofrer a ação dos microrganismos (SCHERER; NESI; MASSOTTI, 2010).

O nitrogênio compõe a molécula de clorofila e de várias vitaminas. Grande parte do nitrogênio encontrado no solo provém de materiais orgânicos mortos, nos quais existe sob a forma de compostos orgânicos complexos, como proteínas, aminoácidos, ácidos nucleicos e nucleotídeos (EMBRAPA, 2004). Entretanto, estes compostos nitrogenados são, em geral, rapidamente decompostos em substâncias mais simples por organismos que vivem nos solos, como bactérias saprófitas e várias espécies de fungos. Estes microrganismos utilizam as proteínas e os aminoácidos como fonte para suas próprias proteínas e liberam o excesso de nitrogênio sob a forma de amônio $\left(\mathrm{NH}_{4}{ }^{+}\right)$. Várias espécies de bactérias comumente encontradas nos solos são capazes de oxidar o amônio transformando-o em nitrito $\left(\mathrm{NO}_{2}{ }^{-}\right)$. O nitrito por sua vez, é tóxico para as plantas superiores, mas raramente se acumula no solo, pois outro gênero de bactéria oxida o nitrito, formando nitrato $\left(\mathrm{NO}_{3}{ }^{-}\right)$, que é a forma sob a qual quase todo o nitrogênio se move do solo para o interior das raízes (MOREIRA; SIQUEIRA, 2002).

O enxofre contribui na formação de alguns aminoácidos e devido a isso, está presente em todas as proteínas vegetais. $\mathrm{O}$ fósforo é um nutriente móvel. Juntamente com o nitrogênio e o potássio, o fósforo atua em particular nos órgãos novos em crescimento, vegetativos ou reprodutivos, que são drenos preferenciais no desenvolvimento das plantas. $\mathrm{O}$ fosfato não causa efeitos por seu excesso, mas sua deficiência proporciona a clorose das plantas (EMBRAPA, 2004). O cálcio é um nutriente absorvido pelas raízes como íons com baixa mobilidade, com consequente aparecimento dos sintomas de deficiência nos tecidos novos das plantas. Por ser um íon imóvel, atua na germinação do grão e no crescimento do tubo polínico, ativa ainda, enzimas relacionadas ao metabolismo do fósforo (EMBRAPA, 2004).

O uso de fertilizantes orgânicos na forma de dejetos de origem animal já é usual no meio agrícola. Contudo, o uso do lodo têxtil e urina humana ainda não são tão difundidos. Ao se avaliar a urina humana, nota-se que a maioria dos nutrientes da excreta se encontra nela. Assim, segundo Esrey et al. (1998), um adulto pode produzir, em média, 500 L/ano de urina, contendo $4000 \mathrm{~g}$ de N, $400 \mathrm{~g}$ de $\mathrm{P}$ e $900 \mathrm{~g}$ de K. Uma das vantagens em se utilizar esse tipo de resíduo é que os nutrientes se encontram na forma ideal para serem aproveitados pelas plantas: o nitrogênio na forma de ureia, o fósforo como ortofosfato e o potássio como ín livre (KIRCHMANN; PETTERSSON, 1995). No caso da sua utilização como fertilizante, pesquisas apontam que um armazenamento superior a 30 dias é suficiente para a eliminação de bactérias patogênicas. Segundo Kiperstok, Nascimento e Kiperstok (2010) este processo ocorre em função da elevação do $\mathrm{pH}$, que ocorre com a hidrólise da ureia na presença da enzima urease. O mesmo autor afirma que para se evitar a perda de nitrogênio pela vaporização da amônia, o armazenamento deve ser em recipiente fechado. Países como a Suécia, por exemplo, já possuem uma legislação vigente para utilização de urina como fonte de adubação, sugerindo que a urina permaneça 


\section{REA - Revista de estudos ambientais (Online) v.18, n. 2, p.52-61, jul./dez. 2016}

estocada por seis meses a um ano antes de ser utilizada em qualquer cultivo alimentício e de forragem e, ainda, áreas de parque. Deve permanecer estocada por um mês pelo menos quando utilizada para cultivos alimentícios que serão processados em cultivos de forragem (KVARNSTRÖM et al., 2006).

É importante ressaltar que a capacidade do solo em receber esses compostos depende da característica formadora e da quantidade de suporte do mesmo.

Em função dos riscos de acúmulo de poluentes no solo, que o tornariam impróprio para a produção de alimentos para o consumo humano, existem diversos parâmetros preconizados por legislações. A aplicação de lodo de esgoto na agricultura deve seguir a resolução 375 (CONAMA, 2006). Ela estabelece a taxa de aplicação máxima anual de lodo de esgoto e produtos derivados, não devendo exceder a relação entre a quantidade de nitrogênio total recomendada para a cultura (em kg. ha ${ }^{-1}$ ), segundo a recomendação agronômica oficial de cada Estado. Segundo Pedroza et al. (2010) e Serrat et al. (2011), o lodo deve passar por tratamentos preliminares de higienização e de estabilização.

Em relação ao DLS, a Fundação de Amparo e Tecnologia ao Meio Ambiente do estado de Santa Catarina (FATMA, 2003), estabelece que a quantidade máxima de dejetos suínos para a utilização em lavouras é de $50 \mathrm{~m}^{3}$. ha ${ }^{-1} \mathrm{ano}^{-1}$, e de acordo com recomendações de adubação indicadas por laudo com base em análise do solo.

Neste contexto, este trabalho tem por objetivo quantificar as espécies químicas aniônicas, catiônicas e carbono dos resíduos da suinocultura, da indústria têxtil e da urina humana, visando o seu reuso como fertilizante na atividade agrícola.

\section{Material e métodos}

Para a execução deste trabalho foram coletadas três amostras dos resíduos da suinocultura, lodo têxtil e urina humana, no período de dezembro 2012 a maio de 2013.

O DLS é composto de fezes, urina, água desperdiçada nos bebedouros e higienização das instalações, restos de ração, pelos e poeira decorrentes do sistema de criação. Sua composição varia de acordo com o manejo da criação (GONÇALVES
JUNIOR et al., 2008; SOUZA et al., 2009). Para fins desta pesquisa, o DLS coletado para análise corresponde ao de uma unidade de produção, localizada no município de Campos Novos-SC, na qual se tem desde a fase de creche até terminação dos suínos.

A urina humana é uma solução constituída de aproximadamente $96 \%$ de água e apenas $4 \%$ de diversas espécies químicas como cloretos, fosfatos, sulfatos, ureia, sódio, amônia potássio entre outros, provenientes da alimentação e do metabolismo de cada ser humano (LIND; BAN; BYDÉN, 2001; VINNERÅS; JÖONSSON, 2002). A urina utilizada para análise foi obtida de voluntários do campus II da Fundação Universidade Regional de Blumenau (FURB).

Os subprodutos sólidos do tratamento de estações de tratamentos de efluentes (ETEs), são comumente chamados de lodo. Desse modo, segundo Pedroza et al. (2010), o lodo têxtil é um resíduo semissólido, de natureza predominantemente orgânica, oriundo de uma estação de tratamento de efluentes. $O$ lodo têxtil analisado nesta pesquisa foi coletado na estação de tratamento de efluentes de uma indústria de artigos têxteis para uso cirúrgico e hospitalar, situada no município de Blumenau - SC. O sistema de tratamento nesta unidade é composto por equalizador, reator biológico e tratamento terciário, este último usado para redução da carga de fósforo. O lodo foi coletado no decantador secundário, que recebe os efluentes do reator biológico.

\subsection{Preparação das amostras}

O DLS e o lodo têxtil foram coletados e posteriormente agitados para tornar a amostra homogênea, retirando-se, em seguida uma alíquota de $15 \mathrm{~mL}$, que foi transferida para um tubo de falcon e centrifugada a $3600 \mathrm{rpm}$ por 30 minutos. Retirou-se do sobrenadante uma alíquota de $1 \mathrm{~mL}$ que foi transferida para um balão volumétrico de $50 \mathrm{~mL}$, completado com água ultrapura obtida em sistema Milli-Q.

$\mathrm{Na}$ preparação da urina humana foi realizada somente a diluição, da mesma maneira que para o lodo têxtil.

\subsection{Determinação das espécies químicas}

Os analitos avaliados foram Cloreto $\left(\mathrm{Cl}^{-}\right)$, Nitrito $\left(\mathrm{NO}_{2}^{-}\right)$, Nitrato $\left(\mathrm{NO}_{3}^{-}\right)$, Sulfato 


\section{REA - Revista de estudos ambientais (Online) v.18, n. 2, p.52-61, jul./dez. 2016}

$\left(\mathrm{SO}_{4}^{-2}\right)$, Fosfato $\left(\mathrm{PO}_{4}^{-3}\right)$, Sódio $\left(\mathrm{Na}^{+}\right)$, Amônia $\left(\mathrm{NH}_{4}^{+}\right)$, Potássio $\left(\mathrm{K}^{+}\right)$, Magnésio $\left(\mathrm{Mg}^{2+}\right)$ e Cálcio $\left(\mathrm{Ca}^{2+}\right)$, e Carbono Total (TC), Carbono Orgânico Total (TOC) e Carbono Inorgânico (IC).


aniônicas e catiônicas, utilizou-se o cromatógrafo de troca iônica, modelo ICS-90, marca DIONEX. Foram utilizadas duas colunas de separação, uma aniônica e outra catiônica, juntamente com supressora e detector de condutividade.

As condições de injeção da amostra, para a coluna aniônica foram: $10 \mu \mathrm{L}$; Temperatura: $30^{\circ} \mathrm{C}$; Taxa de fluxo: $1,2 \mathrm{~mL}$ min. ${ }^{-1}$; Eluente: $\mathrm{Na}_{2} \mathrm{CO}_{3}(4,5 \mathrm{mM})$ e $\mathrm{NaHCO}_{3}$ (1,4 mM); condutividade esperada: $19-23$ SS; Supressor: aniônico auto regenerante; Solução estoque: $\mathrm{NaHCO}_{3}$ (100mM); Corrente aplicada: $31 \mathrm{~mA}$. Para a coluna catiônica as condições de injeção da amostra foram: $25 \mu \mathrm{L}$; temperatura: $30^{\circ} \mathrm{C}$; taxa de fluxo: $0,5 \mathrm{~mL}$ min. ${ }^{-1}$; eluente: $\mathrm{H}_{2} \mathrm{SO}_{4}(20 \mathrm{mM})$; condutividade: $<2 \mu \mathrm{S}$; supressor: catiônico auto regenerante; solução regenerante estoque: TBAOH (tetrabutylammonium) 2,06 $\mathrm{M}$; corrente aplicada: $30 \mathrm{~mA}$. As curvas de calibração foram desenvolvidas a partir dos padrões obtidos junto à DIONEX, utilizandose cinco pontos, na faixa de 1 a $10 \mathrm{mg} \mathrm{L}^{-1}$, com leitura em quintuplicata. As leituras das concentrações foram realizadas em triplicatas.

Para a determinação das concentrações de Carbono Total, Carbono Orgânico Total e Carbono Inorgânico das amostras foi utilizado 0 analisador de carbono orgânico total marca SHIMADZU modelo TOC - $\mathrm{V} \mathrm{CPH}$. As curvas de calibração foram desenvolvidas com padrões obtidos junto à QHEMIS, utilizando-se cinco pontos na faixa de 1 a $100 \mathrm{mg} \mathrm{L}^{-1}$, com leitura em triplicata.

\section{Resultados e discussão}

Os resíduos analisados neste estudo são compostos por micro e macro nutrientes, que agem de maneira diferente nas plantas a fim de suprir as necessidades que a mesma venha a ter em suas diferentes fases de desenvolvimento.

O dejeto líquido de suíno apresentou valores maiores que os encontrados em outros estudos para as espécies químicas sódio, amônio, potássio, cálcio, magnésio, nitrato e carbono orgânico total (Tabela 1). O nitrito e o fosfato apresentaram valores inferiores a média aritmética dos valores encontrados na literatura consultada. A urina humana apresentou valores acima da média para o sódio, nitrito, nitrato e carbono orgânico e, menores para amônio e potássio. No caso do lodo têxtil, todas as concentrações ficaram abaixo dos valores citados na literatura consultada (BOLZANI; OLIVEIRA; LAUTENSCHLAGER, 2012; SILVA et al., 2012; MAGGI et al., 2011; LI et al., 2008; BOTTO, 2013; YOSHINAGA et al., 2000; ARAÚJO; MONTEIRO; CARDOSO, 2005; PELISSARI et al., 2009; BETTIOL; FERNANDES, 2004).

Estas variações encontradas nas concentrações das espécies químicas nos resíduos podem ser justificadas pelo fato da disponibilidade das mesmas estar diretamente associada ao sistema de manejo adotado pelo gerador. Fatores como, maturação, sexo, armazenamento dos animais e alimentação fornecida, além de fatores ambientais como temperatura e umidade do ar, incidem diretamente sobre a produção e qualidade dos resíduos animais (SÁNCHEZ; GONZÁLEZ, 2005; SOUZA et al., 2009).

As espécies químicas cloreto, sódio, fosfato, carbono orgânico total e carbono total da urina humana apresentaram valores superiores aos dos resíduos da suinocultura e do lodo têxtil, respectivamente de $6.288,9$, $4.177,88,1.320,86,5.342,80$ e $6.790 \mathrm{mg}^{-1} \mathrm{~L}^{-1}$. $\mathrm{O}$ sódio em grandes concentrações, como encontrado nesse estudo, promove 0 desprendimento de agregados no solo, podendo aumentar a erosão e o cálcio e magnésio facilitam a floculação (DONTSOVA; NORTON 2001; CARVALHO; SOUZA, SOUZA, 2005 ; OLIVEIRA et al., 2012).

A matéria orgânica trás muitos benefícios ao solo. Está ligada ao aumento da disponibilidade dos micronutrientes, melhoria na qualidade física do solo devido à redução da erosão, aumento na retenção de água, melhoria na qualidade biológica do solo devido ao aumento nos teores de carbono e nitrogênio (SCHERER; NESI; MASSOTTI, 2010). Porém, neste estudo, o carbono total e carbono orgânico total determinados estão livres na fase líquida, o que facilitaria a lixiviação, podendo contribuir para a poluição das águas. 


\section{REA - Revista de estudos ambientais (Online) v.18, n. 2, p.52-61, jul./dez. 2016}

Tabela 1 - Concentração das espécies químicas nos resíduos da suinocultura, indústria têxtil e urina humana, comparados ao da literatura

\begin{tabular}{|c|c|c|c|c|c|c|}
\hline \multirow{3}{*}{$\begin{array}{l}\text { Espécies } \\
\text { químicas }\end{array}$} & \multicolumn{2}{|l|}{ Suinocultura } & \multirow{2}{*}{\multicolumn{2}{|c|}{$\begin{array}{l}\text { Urina humana } \\
\mathrm{mg}^{-\mathrm{L}^{-1}}\end{array}$}} & \multicolumn{2}{|l|}{ Lodo têxtil } \\
\hline & \multirow[b]{2}{*}{ Este trabalho } & \multirow[b]{2}{*}{ Referência } & & & & \\
\hline & & & Este trabalho & Referência & Este trabalho & Referência \\
\hline $\mathrm{Na}^{+}$ & $303,10 \pm 45$ & $26,00^{\mathrm{b}, \mathrm{c}}$ & $4177,88 \pm 411$ & $2,352^{\mathrm{e}}$ & $368,66 \pm 31$ & $0,60^{i}$ \\
\hline $\mathrm{NH} 4^{+}$ & $1314,49 \pm 243$ & $466,45^{\mathrm{b}, \mathrm{c}}$ & $267,57 \pm 141$ & $5546,03^{\mathrm{d}, \mathrm{e}, \mathrm{f}}$ & $1,25 \pm 0,2$ & $1,60^{g}$ \\
\hline $\mathrm{K}^{+}$ & $1321,13 \pm 264$ & $333,84^{a, b, c}$ & $1247,88 \pm 114$ & $1607,20^{e, f}$ & $132,64 \pm 32$ & $2,62^{\mathrm{g}, \mathrm{h}, \mathrm{i}}$ \\
\hline $\mathrm{Mg}^{2+}$ & $72,51 \pm 18$ & $49,98^{a, b, c}$ & $98,61 \pm 15$ & & $36,97 \pm 1,67$ & $2,97^{\mathrm{g}, \mathrm{h}, \mathrm{i}}$ \\
\hline $\mathrm{Ca}^{2+}$ & $381,12 \pm 22$ & $88,12^{a, b, c}$ & $416,26 \pm 109$ & & $88,9 \pm 34$ & $15,84^{\mathrm{g}, \mathrm{h}, \mathrm{i}}$ \\
\hline $\mathrm{Cl}^{-}$ & $495,56 \pm 348$ & & $6288,9 \pm 572$ & $6944,73^{\mathrm{e}, \mathrm{f}}$ & $67,11 \pm 12$ & \\
\hline $\mathrm{NO}_{2}^{-}$ & $0,44 \pm 0,39$ & $2,25^{\mathrm{c}}$ & $18,94 \pm 2$ & $6,10^{\mathrm{e}}$ & $0,45 \pm 0,35$ & \\
\hline $\mathrm{NO}_{3}^{-}$ & $20,85 \pm 9$ & $2,18^{b, c}$ & $41,44 \pm 6$ & $5,70^{\mathrm{e}}$ & $6,29 \pm 3$ & $42,93^{g, h}$ \\
\hline $\mathrm{PO}_{4}^{3-}$ & $62,54 \pm 11$ & $291,38^{a, b, c}$ & $1320,86 \pm 105$ & $1327,60^{\mathrm{d}, \mathrm{e}, \mathrm{f}}$ & $31,93 \pm 4$ & $8,65^{g, h}$ \\
\hline $\mathrm{SO}_{4}{ }^{2-}$ & $8,05 \pm 2,2$ & & $986,17 \pm 30$ & & $59,16 \pm 20$ & \\
\hline TOC & $1657,5 \pm 199$ & $758,33^{a}$ & $5342,8 \pm 234$ & $161,00^{d}$ & $64,5 \pm 11$ & $318,27^{i}$ \\
\hline TC & $2996,7 \pm 335$ & & $6790,2 \pm 722$ & & $261,6 \pm 24$ & \\
\hline IC & $1339,2 \pm 238$ & & $1447,3 \pm 557$ & & $197,1 \pm 20$ & \\
\hline
\end{tabular}

Fonte: ${ }^{a}$ Bolzani, Oliveira e Lautenschlager (2012); ${ }^{b}$ Silva et al. (2012), ${ }^{\mathrm{c}}$ Maggi et al. (2011); ${ }^{\mathrm{d}} \mathrm{Li}$ et al. (2008); ${ }^{\mathrm{e}}$ Botto (2013); ${ }^{\mathrm{f}}$ Yoshinaga et al. (2000); ${ }^{\mathrm{g}}$ Araújo, Monteiro e Cardoso (2005); ${ }^{\mathrm{h}}$ Pelissari et al. (2009); 'Bettiol e Fernandes (2004).

\subsection{Reposição dos nutrientes}

A adubação é uma prática agrícola que visa o fornecimento de nutrientes ao solo na forma de adubos ou fertilizantes, de modo a recuperar ou conservar a sua fertilidade, suprindo sua carência e proporcionando o pleno desenvolvimento das culturas vegetais. A adubação pode ser feita através de adubos sintéticos formulados ou orgânicos, como DLS, lodo têxtil e urina humana. A aplicação pode ser feita diretamente no solo, via foliar ou através de irrigação (fertirrigação) nas diferentes fases de desenvolvimento da cultura.

Para obter a produtividade esperada para as diferentes culturas, faz-se necessário conhecer as caraterísticas do solo em relação aos teores de nutrientes disponíveis no mesmo. A mobilidade dos nutrientes disponíveis no solo é afetada por fatores físicos e químicos. Dentre os principais atributos físicos, incluem-se a distribuição relativa do tamanho de poros e seus graus de saturação com água e a quantidade de água que percola no perfil, a qual depende da quantidade e intensidade das chuvas e da capacidade de retenção de água pelo solo. Os principais aspectos químicos são: a concentração da solução no solo, o pH, a capacidade de troca de cátions, as reações de dissolução/precipitação e as trocas iônicas entre os nutrientes que estão na solução com aqueles da fase sólida durante o processo de percolação (BOLZANI; OLIVEIRA; LAUTENSCHLAGER, 2012).

Depois de feita esta análise, é possível classificar as espécies químicas em níveis de disponibilidade, como, muito baixo, baixo e médio. Assim pode-se estimar a quantidade de cada nutriente que a cultura necessita para seu pleno desenvolvimento e aplicar a adubação corretiva (EMBRAPA, 2004).

A quantidade necessária de cada nutriente para o pleno desenvolvimento de determinada cultura é diferente, variando em cada espécie, região e tipo de solo. Porém quando se trata da utilização de resíduos para adubação, a FATMA (2003) determina 


\section{REA - Revista de estudos ambientais (Online) v.18, n. 2, p.52-61, jul./dez. 2016}

quantidades máximas de dejetos que podem ser aplicados.

A utilização dos dejetos nos solos agrícolas é recomendável, mas requer uma combinação cuidadosa e harmoniosa dos princípios da ciência do solo, saúde pública e hidrologia. Para tanto é essencial conhecer a composição química dos dejetos a serem utilizados e as exigências em fertilização dos solos onde os dejetos serão despejados. A
Instrução Normativa $n^{0} 11$ (FATMA, 2003) determina que a quantidade máxima de dejetos para a utilização em lavouras é de 50 $\mathrm{m}^{3} \mathrm{ha}^{-1}$ ano $^{-1}$, e de acordo com recomendações de adubação indicadas por laudo com base em análise do solo.

$\mathrm{Na}$ Tabela 2 estão descritos os valores das espécies químicas em massa correspondentes à aplicação dos resíduos, para atendimento da $\mathrm{IN} \mathrm{n}^{\circ} 11$.

Tabela 2 - Massa equivalente das espécies químicas para atendimento da IN $\mathbf{n}^{\circ} 11$

\begin{tabular}{|c|c|c|c|}
\hline \multirow{2}{*}{$\begin{array}{l}\text { Espécie } \\
\text { química }\end{array}$} & Suinicultura & Lodo têxtil & Urina humana \\
\hline & \multicolumn{3}{|c|}{$\mathbf{k g}$} \\
\hline $\mathrm{Na}^{+}$ & 15,2 & 18,4 & 208,9 \\
\hline $\mathrm{NH}_{4}{ }^{+}$ & 65,7 & 0,1 & 13,4 \\
\hline $\mathrm{K}^{+}$ & 66,1 & 6,6 & 62,4 \\
\hline $\mathrm{Mg}^{2+}$ & 3,6 & 1,8 & 4,9 \\
\hline $\mathrm{Ca}^{2+}$ & 19,1 & 4,4 & 20,8 \\
\hline $\mathrm{Cl}^{-}$ & 24,8 & 3,4 & 314,4 \\
\hline $\mathrm{NO}_{2}^{-}$ & 0,0 & 0,0 & 0,9 \\
\hline $\mathrm{Br}^{-}$ & 0,1 & 0,0 & 0,0 \\
\hline $\mathrm{NO}_{3}^{-}$ & 1,0 & 0,3 & 2,1 \\
\hline $\mathrm{PO}_{4}^{3-}$ & 3,1 & 1,6 & 66,0 \\
\hline $\mathrm{SO}_{4}{ }^{2-}$ & 0,4 & 3,0 & 49,3 \\
\hline TOC & 82,9 & 3,2 & 267,1 \\
\hline TC & 149,8 & 13,1 & 339,5 \\
\hline IC & 67,0 & 9,9 & 72,4 \\
\hline
\end{tabular}

Fonte: Autores (2016)

Observa-se que o lodo têxtil é bastante pobre em relação às espécies químicas exigidas na agricultura, o que pode inviabilizar a utilização deste produto na agricultura, já que seria necessária a aplicação de uma quantidade muito elevada para atender as necessidades das culturas. Uma opção para viabilizar a aplicação deste lodo têxtil na agricultura seria incorporar quantidades de outros resíduos como os dejetos de suínos e urina humana ou ainda fertilizantes químicos para complementar a exigência dos nutrientes para cada cultura. Segundo EMBRAPA (2004), solos classificados com teor muito baixo de fósforo e potássio necessitam $120 \mathrm{~kg}$. ha ${ }^{-1}$ de $\mathrm{P}$ e K para adubação corretiva, solos classificados com baixo teor, necessitam de $60 \mathrm{~kg} \mathrm{ha}^{-1} \mathrm{de}$ $\mathrm{P}$ e K. Se o teor de fósforo e potássio encontrado no solo for considerado médio, a quantidade de $\mathrm{P}$ e $\mathrm{K}$ para reposição deve ser de $30 \mathrm{~kg}$. ha ${ }^{-1}$. Assim, DLS e urina humana supririam a necessidade de $\mathrm{K}$ na faixa média do solo quando da interpretação do seu teor no solo. Para o lodo têxtil, o valor ficou 9 vezes abaixo do necessário para suprir a necessidade da adubação corretiva. Para solos com faixa muito baixa a aplicação de DLS e urina humana podem ser de 100 $\mathrm{m}^{3} \mathrm{ha}^{-1} \mathrm{ano}^{-1}$. Solos com teor médio de $\mathrm{K}$, o DLS e urina humana tem que ser reduzidos pela metade e o lodo têxtil atende as necessidades desde que aplicados 250 $\mathrm{m}^{3} \mathrm{ha}^{-1}$ ano $^{-1}$.

Observando-se a quantidade de fósforo encontrado, a urina humana supriu a necessidade quando o teor deste elemento no solo estiver na faixa media de interpretação, para o DLS o valor observado ficou 20 vezes menor e para o lodo têxtil 37 vezes. Quando for atender a necessidade da faixa de teor muito baixa a urina humana pode ser aplicada na taxa de $100 \mathrm{~m}^{3} \mathrm{ha}^{-1}$ $a_{n o}{ }^{-1}$, porém o DLS e lodo têxtil não atenderiam a necessidade da adubação 


\section{REA - Revista de estudos ambientais (Online) v.18, n. 2, p.52-61, jul./dez. 2016}

corretiva, assim vale salientar o incremento de adubação química.

O nitrogênio, por ser o elemento de maior mobilidade no solo e sofrer uma série de transformações por parte de microorganismos, deve ser o nutriente a receber maior atenção quando utilizados dejetos na adubação. Quando este nutriente for utilizado de forma imprópria na adubação, grande parte do elemento pode alcançar as águas de drenagem e constituir-se em fonte de degradação ambiental.

Em solos tratados com resíduos orgânicos, a mineralização do nitrogênio além de ser altamente dependente da composição do resíduo e das características químicas e físicas do solo que receberá o resíduo, está diretamente relacionada à qualidade do material orgânico, por exemplo, relação carbono/nitrogênio ( $\mathrm{C} / \mathrm{N})$. A relação carbono e nitrogênio esperada fica em torno de 30:1, para que a decomposição dos resíduos se realize com eficiência, e resulte em um material rico em nutrientes e minerais, podendo ser usado como adubo. Caso essa relação seja muito superior, a imobilização pode ocorrer. Alguns autores sugerem que no DLS esta relação é baixa, da ordem de 5:1 ou menor (FEIGIN; FEIGENBAUM; LIMONI, 1991; BOLZANI; OLIVEIRA; LAUTENSCHLAGER, 2012). Neste estudo os valores da relação $\mathrm{C} / \mathrm{N}$ no DLS foram também baixos, corroborando com a literatura pesquisada. No caso da urina humana a relação $\mathrm{C} / \mathrm{N}$ se mostrou um pouco mais elevada, mais ainda abaixo do desejado.

Alguns trabalhos têm se referido à baixa recuperação de nitrogênio pelas culturas quando aplicado ao solo através dos dejetos (YAGÜE; QUÍLEZ, 2010; MEADE et al., 2011), que pode ser atribuído às perdas de $\mathrm{N}$ por lixiviação de nitrato $\left(\mathrm{NO}_{3}{ }^{-}\right)$, volatilização de amônia $\left(\mathrm{NH}_{3}\right)$ e desnitrificação (SUTTON et al., 1982; MOOLEKI et al., 2002; MEADE et al., 2011). Outro problema que pode vir a ser encontrado quando da utilização desses dejetos é a imobilização do nitrogênio ocasionada, por exemplo, pelo excesso de carbono lançado no solo. Quando substâncias orgânicas ricas em carbono, mas pobres em nitrogênio, se encontram em abundância no solo, os microrganismos que degradam estas substâncias utilizarão o nitrogênio disponível como energia a fim de utilizar totalmente o carbono presente, indisponibilizando-o para as plantas (SCHERER; NESI, 2004; MOREIRA;
SIQUEIRA, 2002). Assim, a imobilização microbiana do nitrogênio dos dejetos também pode contribuir para reduzir a disponibilidade do mesmo às culturas (DAUDÉN; QUÍLEZ, 2004).

O fósforo e o potássio, outros dois macros nutrientes essenciais às plantas, são menos móveis no solo e, por isso, menos sujeitos a perdas do que o nitrogênio. O fósforo é praticamente imóvel e acumula na camada superficial do solo; o potássio apresenta uma maior mobilidade, porém também acumula nas camadas superficiais do solo. Ambos os elementos são fortemente fixados e adsorvidos pelas partículas do solo e, por conseguinte, estão presentes em baixas concentrações nas águas de drenagem. Por isso, não constituem maiores fontes de contaminação dos mananciais de água (EMBRAPA, 2004).

Para a utilização racional destes resíduos, de forma econômica e sem maiores prejuízos ambientais, sugere-se maior atenção ao nitrogênio, por ser o elemento mais móvel e com maiores transformações no solo. Deve-se evitar a adição de nitrogênio em quantidades superiores às necessidades da cultura, pois o excedente poderá ser facilmente lixiviado pelas águas de drenagem. Nutrientes com menor mobilidade no solo, como é o caso do fósforo, potássio e zinco, requerem uma menor atenção ambiental, pois não são lixiviados com tanta facilidade. Porém, para se evitar o acúmulo desses nutrientes no solo e o aumento gradual de sua disponibilidade às plantas, que poderá resultar em futuros desequilíbrios nutricional, a EMBRAPA (2006) recomenda a análise periódica dos solos e monitoramento do acúmulo e/ou percolação dos elementos no perfil do solo.

\section{Conclusões}

O dejeto de suíno e a urina humana podem ser empregados como adubo orgânico, desde que tomados os devidos cuidados para evitar os possíveis riscos de contaminação do solo e águas subterrâneas.

Quanto ao lodo têxtil, este é possível de ser utilizado, porém devido às baixas concentrações encontradas de nutrientes necessários ao desenvolvimento das culturas, seria necessária a complementação com fertilizantes químicos. 


\title{
REA - Revista de estudos ambientais (Online) v.18, n. 2, p.52-61, jul./dez. 2016
}

\author{
5 Characterization of swine manure, textile industry waste and human urine for application \\ as a fertilizer
}

\begin{abstract}
The use of organic wastes in agriculture is a viable option in terms of agricultural and economic view, because of nutrient cycling. However, there are questions regarding the environmental impacts that can be generated. This study aimed to quantify the chemical species from swine waste, textile industry waste and human urine, in view of reuse them as fertilizer in agriculture. For determining the concentrations of chemical species, it was used the anionic and cationic ion exchange chromatography and, total organic carbon analyzer for carbon concentrations of the samples. The results indicated that liquid swine manure (LSM) and human urine can supply the need for potassium in soils whose potassium content is considered to be of medium value, while the textile sludge presented value 9 times lower. For soils with very low range, the application of LSM and human urine may be $100 \mathrm{~m}^{3} \mathrm{ha}^{-1}$ ano $\mathrm{o}^{-1}$, while in soils with medium potassium content, DLS and human urine have to be halved. In the case of phosphorus, human urine supplies the need when the content of this element in the soil is medium, while in the LSM the observed value is 20 times smaller and in the textile sludge 37 times smaller. To fulfill the necessity of soils with very low phosphorus content, human urine can be applied at $100 \mathrm{~m}^{3}$. ha ${ }^{-1}$ year ${ }^{-1}$, but LSM and textile sludge would not fulfill this need.
\end{abstract}

Keywords: Liquid swine manure. Waste characterization. Soil fertilization.

\section{Referências}

ARAÚJO, A.S.F.; MONTEIRO, R.T.R.; CARDOSO, P.F. Composto de lodo têxtil em plântulas de soja e trigo. Pesquisa Agropecuária Brasileira, v.40, n.6, p.549-554, 2005.

ARRUDA, C. A. O.; M.V.; MAFRA, A.L.; CASSOL.P.C.; ALBUQUERQUE, J.A.; SANTOS, J.C.P. Aplicação de dejeto suíno e estrutura de um Latossolo vermelho sob semeadura direta. Ciências Agrotecnica, v. 34, n. 4, p. 804-809, 2010.

BASSO, C.J.; CERETTA, C.A.; MORAES, E.M.; GIROTTO, E. Teores totais de metais pesados no solo após aplicação de dejeto líquido de suínos. Ciência Rural, v.42, p.653-659, 2012.

BETTIOL, W.; FERNANDES, S.A.P. Efeito do lodo de esgoto na comunidade microbiana a atributos químicos do solo. Empresa Brasileira de Pesquisa Agropecuária. São Paulo, 2004.

BOLZANI, H.R.; OLIVEIRA, D.L.A.; LAUTENSCHLAGER, S.R. Efeito da aplicação de água residuárias de suinocultura no solo e na qualidade dos seus lixiviados. Engenharia sanitária e ambiental, v. 17 , n. 4 , p. 385-392, 2012.

BOTTO, M.P. Utilização da urina humana como biofertilizante para produção de alimentos e energia: caracterização, uso na agricultura e recuperação de nutrientes. 2013. 270 f. Tese (Programa de Pós-Graduação em Engenharia Civil). Universidade Federal do Ceará, Fortaleza.

CARVALHO, J.C.R. SOUSA, C.S.; SOUSA, C.S. Manual: Fertilizantes e fertilização. Escola de Agronomia - UFBA. 2005, 159 p.
CASSOL, P.C.; COSTA, A.C.; CIPRANDI, O.; PANDOLFO, C.M.; ERNANI, P.R. Disponibilidade de macronutrientes e rendimento de milho em latossolo fertilizado com dejeto suíno. Revista Brasileira de Ciência do Solo, v.36, p.19111923, 2012

CASTRO, E.M.; PEREIRA, F.J.; PAIVA, R. Histologia vegetal: estrutura e função dos órgãos vegetativos. Lavras, Universidade Federal de Lavras, 2009, 34p.

CORRÊA, J.; BENITES, V.M.; REBELLATTO, A. Uso de resíduos animais como fertilizantes. Anais II Simpósio Internacional sobre Gerenciamento de Resíduos Agropecuários e Agroindustriais - II SIGERA 15 a 17 de março de 2011 - Foz do Iguaçu, Paraná.

CONAMA - Conselho Nacional do Meio-Ambiente. Resolução $\mathbf{n}^{\circ} \mathbf{3 7 5}$, de 29 de agosto de 2006. Disponível em: <www.mma.gov.br/port/conama>. Acesso em: 8 ago. 2013.

DAUDÉN, A.; QUílEZ, D. Pig slurry versus mineral fertilization on corn yield and nitrate leaching in a Mediterranean irrigated environment. Eur. J. Agron., 21,p.7-19, 2004.

DONTSOVA, K.; NORTON, L. D. Effects of exchangeable $\mathrm{Ca}: \mathrm{Mg}$ ratio on soil clayflocculation, infiltration and erosion In: Stott, D. E.; Steinhardt, G. C. (eds). Sustaining the Global Farm. 10 International Soil Conservation Organization Meeting, p. 24-29, 2001.

EMPRESA BRASILEIRA DE PESQUISA AGROPECUÁRIA (EMBRAPA). Manual de adubação e de calagem para os Estados do Rio Grande do Sul e de Santa Catarina 


\section{REA - Revista de estudos ambientais (Online) v.18, n. 2, p.52-61, jul./dez. 2016}

Sociedade Brasileira de Ciência do Solo. Comissão de Química e Fertilidade do Solo. - 10. ed. - Porto Alegre, 2004. 400 p.

EMPRESA BRASILEIRA DE PESQUISA AGROPECUÁRIA (EMBRAPA). Sistema Brasileiro de Classificação de Solos. Centro Nacional de Pesquisa de solos. 2 ed. - Rio de Janeiro, 2006, 306 p.

ESREY, S.; GOUGH, J.; RAPAPORT, D.; SAWYER, R.; SIMPSON-HÉBERT, M.; VARGAS, J; WINBLAD, U. Ecological sanitation. Swedish International Development Cooperation Agency, Sida, Stockholm, 1998.

FATMA - Fundação do Meio Ambiente. Instrução Normativa $n^{\circ}$ 11. 2003. Disponível em: <www.fatma.sc.gov.br/download/IN_0312/htm/ln 11(Suinocultura).htm>. Acesso em: 5 ago. 2013.

FEIGIN, A.; FEIGENBAUM, S.; LIMONI, H. Utilization efficiency of nitrogen from sewage effluent and fertilizer applied to corn plants growing in a clay soil. Journal of Environmental Quality, v. 10, p. 284-287, 1991.

GIROTTO, E.; CERETTA, C.A.; LOURENZI, C.R. ; LORENSINI, F.; TIECHER, T.L.; VIEIRA, R.C.B.; TRENTIN, G.; BASSO, C.J.; MIOTTO, A.; BRUNETTO, G. Nutrient transfers by leaching in a no-tillage system through soil treated with repeated pig slurry applications. Nutrient Cycling in Agroecosystems, v. 95, p. 115-131, 2013.

GONÇALVES JUNIOR, A.C.; LINDINO, C.A.; ROSA, M.F.; BARICCATTI, R.; GOMES, G.D. Remoção de metais pesados tóxicos cádmio, chumbo e cromo em biofertilizante suíno utilizando macrófita aquática (Eichornia crassipes) como bioindicador. Acta Scientiarum Technology, v. 30, n. 1, p. 9-14, 2008.

GUARDINI, R.; COMIN, J.J.; SCHMITT, D.E.; TIECHER, T.L.; BENDER, M.A.; SANTOS, D.R.do S.; MEZZARI, C.P.; OLIVEIRA, B.S.; GATIBONI, L.C. BRUNETTO, G. Accumulation of phosphorus fractions in typic Hapludalf soil after long-term application of pig slurry and deep pig litter in a notillage system. Nutrient Cycling in Agroecosystems, v. 93, p. 215 - 225, 2012.

HIGASHIKAWA, F.S.; SILVA, C.A.; BETTIOL, W. Chemical and physical properties of organic residues. Revista Brasileira de Ciência do Solo, v.34, p.1743-1752, 2010.

KIPERSTOK, A.; NASCIMENTO, F.R.A.; KIPERSTOK, A.C. O tratamento em separado da urina e das fezes é uma solução viável ou uma utopia? Revista DAE. v.183, p. 38-43, 2010.

KIRCHMANN, H; PETTERSSON, S. Human urine chemical composition and fertilizer use efficiency. Fertilizer Research. v.40, p.149-154, 1995.
Kvarnström, E.; Emilsson, K.; Stintzing, A. R.; Johansson, M.; Jönsson, H.; Petersens, E.; Schönning, C.; Christensen, J.; Hellström, D.; Qvarnström, L.; Ridderstolpe, P.; Drangert, J Separação de urina: um passo em direção ao saneamento sustentável. Programa EcoSanRes - Instituto Ambiental de Estocolmo, Suécia, 2006. Disponível

em: <http://www.ecosanres.org/pdf files/Urine_Diversi on_Portuguese>. Acesso em: 08 jan. 2014.

LI, F.; BEHRENDT, J.; WICHMANN, K.; OTTERPOHL, R. Resources and nutrients oriented greywater treatment for non-potable reuses. Water Science \& Technology, v. 57, n. 12, p. 1901-1907, 2008.

LIND, B; BAN, Z; BYDÉN, S. Volume reduction and concentration of nutrients in human urine. Ecological Engineering Sweden, v.16, n.4, p.562-566, 2001.

MAGGI, C.F.; FREITAS, P.S.L.; SAMPAIO, S.C.; DIETER, J. Lixiviação de nutrientes em solo cultivado com aplicação de água residuárias de suinocultura. Revista Brasileira Engenharia Agrícola Ambiental, v.15, n.2, p.170-177, 2011.

MEADE, G.; PIERCE, K.; O'DOHERTY, J.V.; MUELLER, C.; LANIGAN, G.; MCCABE, T. Ammonia and nitrous oxide emissions following land application of high and low nitrogen pig manures to winter wheat at three growth stages. Agric. Ecosyst. Environ., 140, p.208-217, 2011.

MENEZES, R.S.C.; SALCEDO. I.H. Mineralização de $\mathrm{N}$ após incorporação de adubos orgânicos em um Neossolo regolítico cultivado com milho. Revista Brasileira de Engenharia Agrícola e Ambiental, v. 11, n. 4 p. 361-367, 2007.

MONDARDO, D.; CASTAGNAR, D.D.; OLIVEIRA, P.S.R; ZOZ, T.; MESQUITA, E.de E. Produção e composição químico-bromatológica da aveia preta fertilizada com doses crescentes de dejeto líquido suíno. Revista Ciência Agronômica, v. 42, n. 2, p. 509-517, 2011.

MOOLEKI, S.P.; SCHOENAU, J.J.; HULTGREEN, G.; WEN, G.; CHARLES, J.L. Effect of rate, frequency and method of liquid swine manure application on soil nitrogen availability, crop performance and $\mathrm{N}$ use efficiency in east-central Saskatchewan. Can. J. Soil. Sci., v.82, p.457467, 2002.

MOREIRA, F.M.S.; SIQUEIRA, J.O. Microbiologia e bioquímica do solo, Lavras, Universidade Federal de Lavras, 2002, 626 p.

NOGUEIRA, T.A.R.; SAMPAIO, R.A.; FONSECA, I.M.; FERREIRA, C.S.; SANTOS, S.E.; FERREIRA, L.C.; GOMES, E.; FERNANDES, L.A. Metais pesados e patógenos em milho e feijão caupi consorciados, adubados com lodo de 


\section{REA - Revista de estudos ambientais (Online) v.18, n. 2, p.52-61, jul./dez. 2016}

esgoto. Revista Brasileira de Engenharia Agrícola e Ambiental, v.11, p.331-338, 2007.

OLIVEIRA, F.P.; BUARQUE, D.C.; VIERO, A.C.; MERTEN, G.H.; CASSOL, E.A.; MINELLA, J.P.G. Fatores relacionados à suscetibilidade da erosão em entressulcos sob condições de uso e manejo do solo. Revista Brasileira de Engenharia Agrícola e Ambiental, v.16, n.4, p.337-346, 2012.

PEDROZA, M.M.; VIEIRA, G.E.G.; SOUSA, J.F.; PICKLER, A.C.; LEAL, E.R.M.; MILHOMEN, C.C. Produção e tratamento de lodo de esgoto - uma revisão. Revista Liberato, v. 11, p. 89-188, 2010.

PELISSARI, R. A. Z.; SAMPAIO, S. C.; GOMES, S. D.; CREPALLI, M.da S. Lodo têxtil e água residuária da suinocultura na produção de mudas de eucalyptus grandis ( $w$, hill ex maiden). Engenharia Agrícola, Jaboticabal, v.29, n.2, p.288-300, 2009.

SÁNCHEZ, M.; GONZÁLEZ, J.L. The fertilizer value of pig slurry. I. Values depending on the type of operation. Bioresource technology, v. 96, n. 10, p. 1117-1123, 2005.

SANTOS, R.C.; MEURER, E.J. Microrganismos em percolado, após aplicações de dejetos líquidos de suínos. Bioscience journal, v. 28, n. 6, p. 1000-1006, 2012.

SCHERER, E.E.; BALDISSERA, I.T.; NESI, C.N. Propriedades químicas de um latossolo vermelho sob plantio direto e adubação com esterco de suínos. Revista Brasileira de Ciência do Solo, v. 31 , n. 1, p. 123-131, 2007.

SCHERER, E. E.; NESI, C. N.; MASSOTTI, Z. Atributos químicos do solo influenciados por sucessivas aplicações de dejetos suínos em áreas agrícolas de Santa Catarina. Revista Brasileira de Ciência do Solo, v. 34, n. 4, p. 1375-1383, 2010.

SCHERER, E.E.; NESI, C.N. Alterações nas propriedades químicas dos solos em áreas intensivamente adubadas com dejetos suínos. In: reunião brasileira de fertilidade do solo e nutrição de plantas, 26., 2004. Lajes. Anais... SBCS/UDESC.

SEIDEL, E.P.; GONÇALVES JUNIOR, A.C.; VANIN, J.P.; STREY, L.; SCHWANTES, D.; NACKE, H. Aplicação de dejetos de suínos na cultura do milho cultivado em sistema de plantio direto. Acta Scientiarum. Technology, v. 32, n. 2, p. 113-117, 2010.

SERRAT, B.M.; SANTIAGO, T.R.; BITTENCOURT, S.; MOTTA, A.C.V.; SILVA, L.A.T.P.; ANDREOLI, C.V. Taxa de aplicação máxima anual de lodo de esgoto higienizado pelo processo de estabilização alcalina: estudo comparativo de curvas de $\mathrm{pH}$ de solos. Revista Brasileira de Ciências Ambientais, n. 19, p. 3039, 2011.

SILVA, D.F.; ANDRADE, C.L.T.; RESENDE, A.V.; HICKMANN, C.; AMARAL, T. A.; ALVES, M.E.B. Nitrogen dynamics in soils cultivated with maize and fertilized with pig slurry. Revista Ambiente \& Água, v. 7, n. 1, p. 9-23, 2012.

SOUZA, C.de F.; CARVALHO, C.da C.S.; CAMPOS, J.A.; MATOS, A.T.; FERREIRA, W.P.M. Caracterização de dejetos de suínos em fase de terminação. Revista Ceres, p. 128-133, 2009.

SUTTON, A.L.; NELSON, D.W.; HOFF, J.D.; MAYROSE, V.B. Effects of injection and surface applications of liquid swine manure on corn yield and soil composition. J. Environ. Qual., v.11, p.468-472, 1982.

VINNERÅS, B.; JÖONSSON, H. The performance and potential of faecal separation and urine diversion to recycle plant nutrients in household wastewater. Bioresource Technology, 84 p. 275 $-282,2002$.

YOSHINAGA J.; CHATTERJEE A.; SHIBATA, Y.; MORITA M.; EDMONDS J.S. Human urine certified reference material for arsenic speciation. Clinical Chemistry, v. 46 , n. 11 , p. 1781-1786, 2000.

YAGÜE, M.R.; QUÍLEZ, D. Direct and residual response of wheat to swine slurry application method. Nutr. Cycl. Agroecossyst., v.86, p.161174, 2010.

\section{Agradecimentos}

Os autores agradecem a FAPESC (Termo de Outorga 17419/2011-0) e ao CNPq (processos 403739/2013-6 e 303472/2014-6), pelo fomento a pesquisa e pela concessão de bolsa de produtividade de pesquisa. 